\title{
Title
}

Cohort Profile: HABITAT - a longitudinal multilevel study of physical activity, sedentary behaviour and health and functioning in mid-to-late adulthood

\section{Author list}

Gavin Turrell, ${ }^{1 *}$ Andrea Nathan, ${ }^{2}$ Nicola W Burton, ${ }^{3}$ Wendy J Brown, ${ }^{4}$ Paul McElwee, ${ }^{5}$ Adrian G Barnett, ${ }^{6}$ Nancy A Pachana, ${ }^{7}$ Brian Oldenburg, ${ }^{8}$ Jerome N Rachele, ${ }^{9}$ Katrina Giskes, ${ }^{10,11}$ Billie Giles-Corti, ${ }^{1}$.

${ }^{1}$ Centre for Urban Research, RMIT University, Melbourne.

${ }^{2}$ Telethon Kids Institute, Perth.

${ }^{3}$ School of Applied Psychology, Griffith University, Brisbane.

${ }^{4}$ School of Human Movement and Nutrition Sciences, The University of Queensland, Brisbane.

${ }^{5}$ School of Public Health, The University of Queensland, Brisbane.

${ }^{6}$ School of Public Health and Social Work, Queensland University of Technology, Brisbane.

${ }^{7}$ School of Psychology, The University of Queensland, Brisbane

${ }^{8}$ Melbourne School of Population and Global Health, University of Melbourne, Melbourne

${ }^{9}$ College of Health and Biomedicine, Victoria University, Melbourne

${ }^{10}$ School of Medicine, University of Notre Dame, Sydney

${ }^{11}$ Heart Research Institute, Charles Perkins Centre, University of Sydney, Sydney

*Corresponding author

Word count: 2990 


\section{Profile in a Nutshell}

- The benefits of physical activity in reducing the risk of non-communicable disease and promoting healthy ageing are well documented. Most Australians, however, do not engage in sufficient activity to accrue health benefits, and activity tends to decline with age.

- HABITAT was established to advance our understanding of the patterns and determinants of physical activity (and sedentary behavior) as the bases for informing policy designed to improve population health and supporting healthy ageing.

- HABITAT is a multilevel prospective observational study of change in physical activity and sedentary behaviour and associated health outcomes, and investigates the relative contributions of environmental, social, psychological, and sociodemographic factors, to these changes.

- The HABITAT study is conducted in the Local Government Area of Brisbane, Australia. Baseline data were collected in 2007 from 200 neighbourhoods ( $\mathrm{n}=11,035$ participants, $68.4 \%$ response rate).

- The baseline sample was aged 40 - 65 years and sociodemographically representative of the Brisbane population within this age-range.

- Since baseline, follow-up has comprised self-completed questionnaires in 2009 ( $n=7,866$, $72.6 \%$ response rate), $2011(\mathrm{n}=6,900,67.6 \%), 2013(\mathrm{n}=6,520,67.6 \%)$ and $2016(\mathrm{n}=5,187$, $58.8 \%$ ) administered by mail survey to the main cohort, and two home-based clinical assessments of a subsample in $2014(n=767,54.6 \%$ response rate) and 2016/17 $(n=606$, $79.0 \%)$.

- Main categories of data collected include physical activity and sedentary behaviours; physical health and psychological wellbeing; physical functioning; risk factors; transport behaviour; sociodemographics; psychological (intrapersonal) and social (interpersonal) influences on physical activity; neighbourhood environment (objective and subjective); natural experiments (e.g. residential relocation); census-derived population profiles; measures using accelerometers and geographic positioning systems.

- Researchers interested in collaborating with the HABITAT Chief Investigators and accessing the data should contact the Lead Investigator, Professor Gavin Turrell (gavin.turrell@rmit.edu.au). 


\section{Why was the cohort set up?}

The benefits of physical activity in reducing the risk of non-communicable diseases are well documented $(1,2)$. Physical inactivity contributes to 6 to $10 \%$ of the burden of coronary heart disease, type 2 diabetes, and breast and colon cancers $(1,3)$. Physical activity helps reduce waist circumference, blood pressure, and cholesterol $(2,4)$, and may play a key role in the prevention and management of poor mental health (5). Recent evidence demonstrates that regular physical activity is particularly important for healthy ageing (6-8). Physical activity at older ages reduces the risk of falls, musculoskeletal conditions, disability and functional/cognitive decline, anxiety and depression; and promotes longevity, health-related quality of life, and wellbeing (9). Thus, understanding the patterns, prevalence and determinants of physical activity participation is key to understanding population health and healthy ageing.

Ecological models of health behaviour posit that there are multiple levels of influence on physical activity, including individual (e.g., biological, psychological), social (e.g., social support and norms), organisational (e.g., social institutions), environmental (e.g., neighbourhood walkability, recreational facilities) and policy (e.g., legislation) (10). These models provide a framework for understanding the multiple and interacting determinants of physical activity, which in turn can inform comprehensive interventions that target individuals and the environments in which they live (11-12).

Few studies have been designed to prospectively assess the multilevel determinants of physical activity (i.e., simultaneously examining area-, group- and individual-level effects on physical activity outcomes) (13-15). Those that do rely primarily on secondary (i.e. published) data sources, thus lacking the data to study specific physical activities and the environments and contexts relevant for those activities (16). Further, although other large prospective studies include measures of physical activity, few have investigated the influence of multilevel factors in the context of change in people's activity levels over time as they age (17-19). 
The HABITAT Study commenced in 2007 with a cohort of men and women aged 40 to 65 years $(n=11,035)$ living in 200 neighbourhoods in the Brisbane Local Government Area, Australia. Funded by two nationally competitive project grants, the overarching aim of Phase One of HABITAT was to examine change in physical activity, and investigate the relative contributions of environmental, social, psychological, and sociodemographic factors, to these changes (Figure 1). Additional funding awarded in 2013 allowed an expansion of focus (Phase Two) to include objective assessment of physical activity, sedentary behaviour and physical functioning. Sedentary behaviours are defined as any waking activities characterised by an energy expenditure $\leq 1.5$ METs in a sitting or reclining posture (20). The MET (metabolic equivalent of task) is a measure of energy expenditure whilst engaging in an activity, relative to energy expenditure at rest. Sedentary behaviours have synergistic effects with physical activity, and have been associated with a range of outcomes relevant to healthy ageing (21-25) The primary objectives of Phase Two were to assess the role of physical activity and sedentary behaviours in preventing, delaying, or accelerating declines in physical function as people age; and to examine how associations between physical activity, sedentary behaviour, and trajectories of physical functioning are influenced by environmental, social, psychological, and sociodemographic factors.

\section{[Insert Figure 1]}

\section{Who is in the cohort?}

Initial sample selection used a two-stage design, whereby study areas were selected first, and individuals chosen subsequently (see Burton et al. (26) for more detail). Study areas were Australian Bureau of Statistics (ABS) Census Collection Districts (CCD), each of which typically contains approximately 200 dwellings in urban areas (27). CCDs were ranked into deciles using the ABS' Index of Relative Socioeconomic Disadvantage (IRSD) (28), with twenty areas per decile randomly selected ( $n=200)$. A CCD's IRSD score reflects the area's overall level of disadvantage measured based on multiple social and economic components including education, 
occupation, income, unemployment, household structure, motor vehicle availability. Using systematic probability sampling without replacement and proportional to the number of households per CCD with at least one person aged 40 to 65 years, an average of 85 households per area were selected, and one person per household was randomly chosen to participate. A structured self-administered questionnaire was developed (available at https://cur.org.au/project/habitat/) and copies were sent to 17,000 potentially eligible participants in May 2007 using a mail survey methodology developed by Dillman (29). Completed questionnaires were returned by 11,035 eligible participants, with 841 refusals and 4,251 nonresponders (response $=68.4 \%$ ). Compared with 2006 census data, the socio-demographic characteristics of the HABITAT cohort at baseline were broadly representative of the Brisbane population aged 40 to 65 years (Table 1).

[Insert Table 1]

\section{How often have they been followed up?}

Since the baseline data collection in 2007, the cohort (i.e. those who responded in 2007 and who hadn't actively withdrawn) have been approached to complete four follow-up surveys (2009, 2011, 2013 and 2016). Surveys were sent out in winter (May to July) each time to minimise potential seasonal effects on physical activity (30-32). Participants who relocated from their baseline address to elsewhere in Brisbane or Australia ("movers") remained eligible to participate, and as at $2016,17.4 \%(n=1,916)$ of the HABITAT cohort has changed address on at least one occasion.

Multiple strategies were used to optimise cohort maintenance, including: personalised communication; the collection of contact details about a family member or friend who didn't live with the participant in case the participant moved or contact was lost; a study newsletter and Christmas card; the inclusion of a change-of-address card with most correspondence; a study website, email address, and free-call phone number, and; the use of survey front-covers that were 
customised for each suburb to orient participants to provide data about their local area rather than Brisbane in general.

At Wave 5 in $2016,77.8 \%(n=8,588)$ of the baseline participants remained in the study, and $22.2 \%(n=2,447)$ were classified as 'withdrawn' for a range of reasons: voluntarily withdrew $(n=1,474)$, deceased $(n=311)$, moved overseas $(n=75)$, physical or cognitive incapacity $(n=49)$, language impairment $(n=8)$ and lost to follow-up/uncontactable $(n=530)$. The proportion of participants who did not return a survey after five attempts to contact them via postal letter (classified as 'non-respondents') has risen incrementally across each successive follow-up wave (Table 2). Analysis of study attrition shows that loss to follow-up has been higher for older persons, the least educated, blue collar workers and persons not in the labour force, and members of lower income households.

\section{[Insert Table 2]}

As part of Phase Two, a sub-sample was randomly selected and invited to take part in a physical function sub-study in 2014. The sub-study assessments were conducted individually at a time and location negotiated with participants, and typically occurred at their residence. Assessments were conducted from July to February, with participants interviewed at approximately the same time of year at each wave of assessment. From the 1,559 HABITAT respondents invited to participate, 154 were deemed ineligible ( $n=49$ no longer living in selected study area; $n=96$ no valid phone number/unable to contact; $n=3$ deceased; $n=6$ unable to stand or walk without assistance/language difficulties) and 767 were assessed in 2014/2015 (response $=54.6 \%)$. Follow-up assessments were completed in 2016/17 $(\mathrm{n}=606$, response $=79.0 \%)$. Socio-demographic characteristics of the sub-sample at baseline and first follow-up are in Table 3 


\section{What has been measured?}

\section{Self-reported measures (mail survey)}

Baseline survey measures were pilot tested and assessed for test-retest reliability (34), and new items used in follow-up surveys are based on validated measures (where possible). In addition to assessing multilevel determinants specific to physical activity, other items included in the survey relate to healthy ageing, socio-economic disadvantage, social determinants of health, life events, psychological wellbeing, transportation, and health (physical and mental).

Given the complexity of physical activity behaviour, several domain-specific measures were incorporated in the survey. Items from the Active Australia survey assess the frequency and total time spent during the previous week (i) walking for recreation, exercise or to get to or from places, (ii) doing vigorous gardening or heavy work around the yard, (iii) doing vigorous physical activity (e.g., jogging) and (iv) other more moderate physical activity (e.g., slow swimming) (35). These items have acceptable levels of reliability and validity and have been recommended for use in population-based monitoring of physical activity in Australia $(36,37)$. In addition, we measured frequency of participation in each of 15 specific active recreation pursuits (e.g., running, tennis, etc.) which were derived from the Exercise, Recreation and Sport Survey (38), and the total time spent in the previous week walking for transport, cycling for transport, walking for recreation, and cycling for recreation. Sedentary behaviour is assessed as sitting time (hours, minutes) on a usual weekday and weekend day across four domains: whilst travelling, watching television (including gaming), in general leisure, and using a computer at home. This measure has been shown to be more reliable and valid for weekdays than weekends, and more valid for assessment of sitting at work, watching television, and computer use at home, than for other domains (39). In 2013 and 2016 self-reported physical functioning was assessed using the 10 item Physical Functioning Scale (PF-10), a component of the Short Form 36 Health Survey (40). The PF-10 has been extensively 
validated (41) and measures a hierarchical range of difficulties, from vigorous activities such as lifting heavy objects to bathing and dressing.

Participants who moved to a different address between data collection waves were sent a survey that contained additional questions to those included in the non-movers survey. The questions asked about the reasons for moving (e.g. to buy a bigger home; commence a new job; relationship breakdown) and the reasons for choosing the new address (e.g. closeness to work, childcare, public transport, plus others). These data were used to measure residential selfselection, which we defined as moving to a neighbourhood that was consistent with ones' preferences, life-stage, circumstances, or socio-demographic charactersitics. Self-selection is a potential confounder of the association between environmental factors and health, and represents one of the biggest threats to claims of causal inference (42), hence measuring self-selection allowed this to be accounted for in analyses.

\section{Objective measures of the environment}

At each of the five time-points corresponding to the survey data collections, a suite of objective environmental measures was generated using a Geographic Information System (GIS). The built environment measures (i.e. residential density, street connectivity, land-use mix, street lights, bikeways, and parks) were generated at four scales: (i) $1 \mathrm{~km}$ Euclidean (straight-line) buffer around each participant's home; (ii) $1 \mathrm{~km}$ road network buffer around each participant's home;

(iii) Census Collector District and; (iv) suburb. GIS was also used to create road network distances from the participant's home to the Brisbane Central Business District, the Brisbane River and coast, the closest public transport node (i.e. bus stop, train station, ferry terminal), shop, public open space, and CityCycle station (public bicycle-hire scheme). In addition, at each of the four built environment scales, we generated measures of crime, topography, and traffic density, and for CCDs we derived an area-level measure of disadvantage using the ABS' IRSD (28). 


\section{Objective measures of individuals}

Individual-level data in the main cohort study have been linked to mortality records. As part of the HABITAT sub-study we measured blood pressure and resting heart rate, height, weight, and waist circumference. Physical functioning was measured based on static balance using the Short Physical Performance Battery measure; grip strength; and functional fitness using the Seniors Fitness Test (upper and lower body muscular strength, aerobic endurance, upper and lower body flexibility, agility and dynamic balance) (43-46). All measurements were taken by research assistants trained to follow a standard protocol. Sub-study participants also wore an Actigraph GT3X-BT accelerometer and QStarz BT-Q1000XT Global Positioning Systems (GPS) device during waking hours for seven days.

\section{What has been found to date? Key findings}

A list of publications arising from the HABITAT study to date is available online (https://cur.org.au/project/habitat/).

Physical activity: Baseline evidence shows that residents of socioeconomically disadvantaged neighbourhoods report lower levels of total physical activity, general walking, and moderate and vigorous activity; however, they are more likely to walk for transport (47). Propensity to walk for transport declines with age; however, the declines are more precipitous for older persons, members of lower income households, and residents of disadvantaged neighbourhoods (48). Higher levels of walking for transport in disadvantaged neighbourhoods are associated with living in a built environment more conducive to walking (i.e. greater street connectivity, more diverse land use mix) (49). In the mid-to-older-age population, walking for transport at levels consistent with physical activity recommendations is more likely in neighbourhoods characterised by greater residential density, access to bikeways, proximity to public transport and shops, and living in a well-lit area (50). Moreover, compared with traditional suburban developments, transport walking 
(and other active modes such as cycling and public transport use) are more likely in 'Transit Oriented Developments', which are urban forms that integrate mixed land use, a relatively dense built environment, well connected street networks, and pedestrian-friendly infrastructure around a transport node (e.g. train station, bus transit centre) (51). Recent longitudinal findings show that investments in changing the built environment to be more walkable are associated with increased walking for transport (52). At the individual-level, our work shows that social and group contexts influence propensity to engage in recreational physical activity (53-55); for example, older people prefer activities with others of a similar age, but are less likely than their younger counterparts to express a preference for fixed-time and structured activity sessions; and persons from low income households are more likely to express a preference for low-cost and team-based activities (56). Among the mid-to-older age population in Brisbane in 2007, approximately $20 \%$ cycled for recreation and $4 \%$ for transport (57). A diverse range of environmental (built and social) and individual-level factors (e.g. socio-demographics, perceptions) are associated with cycling, and the determinants of recreational and transport cycling are often different (58).

Sedentary behaviour: Cross-sectional evidence shows that sedentary leisure is largely independent of physical activity level and does not preclude meeting physical activity recommendations (59). Those who report longer sitting times (especially watching TV) are likely to be male, single and living alone, experience health problems, be less educated, not in paid employment, and be overweight (60). Longitudinal findings show that despite overall total sittingtime remaining stable between 2007 and 2013, significant increases were observed in some domains (e.g. home computer use, TV viewing) and in some sub-groups (e.g. women and the unemployed). These increases were countered by declines in work-related sitting due to retirement (61).

Greenspace: Evidence linking urban greenspace and mental health and wellbeing is growing and gaining recognition in planning policies and mental health services (62). Using a causal-inference 
longitudinal design we contributed to this evidence by showing that within-person perceptions of increases in neighbourhood greenspace were associated with improvements in mental health over three years; conversely, persons who perceived a decline in surrounding greenspace reported a decrease in wellbeing (63).

Parks and public open space: Among mid-to-older aged Brisbane residents, park use is higher among dog walkers, couples with children, and residents of more socioeconomically advantaged areas (64). Park users are more likely to meet physical activity guidelines than non-users, and users of larger-sized neighbourhood and district-catchment parks spend more time doing vigorous activity and engage in more activity sessions than non-users. People who use parks or beaches for physical activity, and those who live within close walking distance to a river or the coast, are more likely to express support for nature conservation as measured by willingness to sacrifice for the environment (e.g. accept reductions in standard of living, salary, and higher taxes and prices to fund environmental initiatives) (65).

Body Mass Index: Prospective assessments of BMI show that consistent use of active travel (i.e. walking and cycling) is associated with lower BMI (66), and that changes in transport mode from passive to active (e.g. motor vehicle use to walking) are associated with reductions in BMI (67). However, to date, we have found no compelling evidence that moving to a new neighbourhood is associated with within-person change in BMI (68) or that weight changes are associated with arealevel characteristics (69).

Health inequalities: Cross-sectional multilevel analyses show that residents of socioeconomically disadvantaged neighbourhoods are more likely to report: poorer self-rated health (70); chronic arthritis (71); tobacco consumption (72); being diagnosed with type 2 diabetes, heart disease, and comorbidity (73), and; lower levels of physical function (74). Neighbourhood disadvantage was associated with these outcomes after adjustment for within-neighbourhood variation in individual- 
level SEP (i.e. education, occupation, household income) suggesting that features of the neighbourhood environment are associated with these inequalities.

\section{What are the study's main strengths and weaknesses?}

The main strengths of HABITAT include its longitudinal multi-level study design and focus on physical activity, a key health-related behaviour relevant to many physical and psychological health outcomes. Unique internationally, HABITAT includes a wide-range of self-report and objectively assessed determinants of physical activity, many measured at multiple scales, and most measured at five time-points between 2007 and 2016. All of HABITAT's GIS data have been captured at each of the survey time-points, thus permitting us to examine how changing environments influence change in behaviour and health. The study's large, population-based sample and relatively high retention rate has produced findings that are representative and generalizable to the Brisbane population of 'baby boomers'.

HABITAT is an observational cohort study based primarily on self-report data and hence subject to all the biases and limitations inherent in this design. As is the case with most cohort studies, response rates have decreased over time. Differential attrition has led to an overrepresentation of higher socioeconomic groups. Although designed as a longitudinal multilevel study of physical activity, some determinants - especially within the psychological and social domains - focus on recreational activity and may not pertain to other activity domains (e.g. active transport). Further, despite measuring sedentary behaviour as an outcome, HABITAT was not purpose-designed to examine the multilevel determinants of this behaviour.

\section{Can I get hold of the data? Where can I find out more?}

For researchers interested in collaborating on data analyses with the Chief Investigators, enquiries can be submitted to the Lead Investigator, Professor Gavin Turrell (gavin.turrell@ @mit.edu.au). 


\section{Funding}

Phases 1 and 2 of HABITAT were funded by three Australian National Health and Medical Research Council (NHMRC) Project Grants [\#339718, \#497236, \#1047453]. BGC is supported by an NHMRC Senior Principal Research Fellowship (\#1107672).

\section{References}

1. Lee IM, Shiroma EJ, Lobelo F, Puska P, Blair SN, Katzmarzyk PT. Effect of physical inactivity on major non-communicable diseases worldwide: an analysis of burden of disease and life expectancy. Lancet 2012;380(9838):219-229.

2. Reiner M, Niermann C, Jekauc D, Woll A. Long-term health benefits of physical activity - a systematic review of longitudinal studies. BMC Public Health 2013;13:813.

3. Kyu HH, Bachman VF, Alexander LT, et al. Physical activity and risk of breast cancer, colon cancer, diabetes, ischemic heart disease, and ischemic stroke events: systematic review and dose-response meta-analysis for the Global Burden of Disease Study 2013. BMJ $2016 ; 354$.

4. Warburton DER, Nicol CW, Bredin SSD. Health benefits of physical activity: the evidence. CMAJ 2006;174:801-809.

5. Jacka FN, Mykletun A, Berk M. Moving towards a population health approach to the primary prevention of common mental disorders. BMC Medicine 2012;10:149.

6. Rillamas-Sun E, LaMonte MJ, Evenson KR, et al. The influence of physical activity and sedentary behavior on living to age 85 years without disease and disability in older women. J Gerontol A Biol Sci Med Sci 2018;73:1525-1531.

7. Sowa A, Tobiasz-Adamczyk B, Topor-Madry R, Poscia A, La Millia DI. Predictors of healthy ageing: public health policy targets. BMC Health Serv Res 2016;16:289 doi:10.1186/512913-016-1520-5. 
8. Olanrewaj O, Kelly S, Cowan A, Brayne C, Lafortune L. Physical activity in community dwelling older people: a systematic review of reviews of interventions and context. PLoS One 2016;11:e0168614.

9. Bauman A, Merom D, Bull F, Buchner D, Fiatarone Singh M. Updating the evidence for physical activity: summative reviews of the epidemiological evidence, prevalence, and interventions to promote "active aging”. Gerontologist 2016;56:S268-S80.

10. Sallis J, Owen N, Fisher E. Ecological Models of Health Behavior. In: Glanz K, Rimer B, Viswanath K, editors. Health Behavior and Health Education: Theory, Research, and Practice. San Francisco: Jossey-Bass; 2008. p. 465-85.

11. Feuillet T, Charreire A, Menai M, et al. Spatial heterogeniety of the relationships between environmental characteristics and active commuting: towards a locally varying social ecological model. Int J Health Geogr 2015;14(1):12. doi: 10.1186/s12942-015-0002-z

12. Sallis J, Owen N. Ecological Models of Health Behavior. In Glanz K, Rimer B, Viswanath K, editors. Health Behavior: Theory, Research and Practice ( $5^{\text {th }}$ edition). San Francisco: Jossey-Bass; 2015. p. 43-64.

13. Giles-Corti B, Knuiman M, Timperio A, et al. Evaluation of the implementation of a state government community design policy aimed at increasing local walking: Design issues and baseline results from RESIDE, Perth Western Australia. Prev Med 2008;46:46-54.

14. Nathan A, Wood L, Giles-Corti B. Exploring Socioecological Correlates of Active Living in Retirement Village Residents. Journal of Aging and Physical Activity 2014;22:1-15.

15. Diez Roux AV. A glossary for multilevel analysis. J Epidemiol Community Health 2002;56:588-594.

16. Giles-Corti B, Timperio A, Bull F, Pikora T. Understanding Physical Activity Environmental Correlates: Increased Specificity for Ecological Models. Exerc Sport Sci Rev 2005;33:175-181. 
17. Bijnen FCH, Feskens EJM, Caspersen CJ, Mosterd WL, Kromhout D. Age, Period, and Cohort Effects on Physical Activity Among Elderly Men During 10 Years of Follow-up: The Zutphen Elderly Study. Journal of Gerontology: Series A 1998;53A:M235-M241.

18. Parsons T, Power C, Manor O. Longitudinal Physical Activity and Diet Patterns in the 1958 British Birth Cohort. Med Sci Sports Exerc 2006;38:547-554.

19. Bennett KM. Gender and longitudinal changes in physical activities in later life. Age Ageing 1998;27 Suppl 3:24-28.

20. Sedentary Behaviour Research. Letter to the Editor: Standardized use of the terms “sedentary" and "sedentary behaviours". App Physiol Nutr Metab 2012;37:540-542.

21. Dickins KA, Buchholz SW, Rivero T, Miller C. A review of reviews: Sedentary behaviour and cardiovascular disease specific to older people. Int J Older People Nurs 2018;13:e12211.

22. Patterson R, McNamara E, Tainio M, et al. Sedentary behaviour and risk of all-cause, cardiovascular and cancer mortality, and incident type 2 diabetes: a systematic review and dose response meta-analysis. Eur J Epidemiol 2018;33:811-829.

23. Boberska M, Szczuka Z, Kruk M, et al. Sedentary behaviours and health-related quality of life. A systematic review and meta-analysis. Health Psychology Review 2018;12:195-210.

24. Zhai L, Zhang Y, Zhang D. Sedentary behaviour and the risk of depression: a meta-analysis. Br J Sports Med 2015;49:705-709.

25. Edwardson CL, Gorely T, Davies MJ, et al. Association of Sedentary Behaviour with Metabolic Syndrome: A Meta-Analysis. PLoS ONE 2012;7:e34916.

26. Burton N, Haynes M, Wilson L, et al. HABITAT: A longitudinal multilevel study of physical activity change in mid-aged adults. BMC Public Health 2009;9:76 doi:10.1186/1471-2458-9-76. 
27. Australian Bureau of Statistics. Australian Statistical Geography Standard (ASGS): Volume 1 - Main Sturcture and Greater Capital City Statistical Areas, July 2016. Canberra: Commonwealth of Australia; 2016.

28. Australian Bureau of Statisitics. Technical Paper. Socio-conomic Indexes for Areas (SEIFA), 2011. Cat. No. 2033.0.55.001. Canberra: Commonwealth of Australia; 2013.

29. Dillman DA. Mail and Internet Surveys: The Tailored Design Method. New York: John Wiley \& Sons; 2000.

30. Tucker P, Gilliland J. The effect of season and weather on physical activity: a systematic review. Public Health 2007;121:909-922.

31. O’Connell S, Griffiths P, Clemes S. Seasonal variation in physical activity, sedentary behaviour and sleep in a sample of UK adults. Ann Hum Biol 2014;41:1-8.

32. Hagströmer M, Rizzo N, Sjöström M. Associations of season and region on objectively assessed physical activity and sedentary behaviour. J Sports Sci 2014;32:629-633.

33. Charlton C, Rasbash J, Brown WJ, Healy M, Cameron B. 2019. MLwiN Version 3.04. Centre for Multilevel Modelling, University of Bristol.

34. Turrell G, Haynes M, O'Flaherty M, Burton N, Giskes K. Test-Retest Reliability of Perceptions of the Neighborhood Environment for Physical Activity by Socioeconomic Status. J Phys Act Health 2011;8:829-840.

35. Armstrong T, Bauman A, Davies J. Physical Activity Patterns of Australian Adults Canberra: Australian Institute of Health and Welfare; 2000.

36. Brown W, Bauman A, Chey T, Trost S, Mummery K. Comparison of surveys used to measure physical activity. Aust N Z J Public Health 2004;28:128-134.

37. Brown W, Trost S, Bauman A, Mummery K, Owen N. Test-retest reliability of four physical activity measures used in population surveys. J Sci Med Sport 2004;7:205-215. 
38. Australian Sports Commission. The Exercise, Recreation and Sport Survey (ERASS) Canberra: Standing Committee on Recreation and Sport; 2010.

39. Marshall AL, Miller YD, Burton NW, Brown WJ. Measuring Total and Domain-Specific Sitting: A Study of Reliability and Validity. Med Sci Sports Exerc 2010;42:1094-1102.

40. Ware JE, Sherbourne CD. The MOS 36-item Short-Form Health Survey (SF-36) Conceptual Framework and Item Selection. Med Care 1992;30:473-483.

41. Bohannon RW, DePasquale L. Physical Functioning Scale of the Short-Form (SF) 36: Internal Consistency and Validity with Older Adults. Journal of Geriatric Physical Therapy 2010;33:16-18.

42. Boone-Heinonen J, Gordon-Larsen P, Guilkey DK, Jacobs Jr, DR, Popkin BM. Environment and physical activity dynamics: the role of residential self-selection. Psychology of Sport and Exercise 2011;12:54-60.

43. Guralnik JM, Simonsick EM, Ferrucci L, et al. A Short Physical Performance Battery Assessing Lower Extremity Function: Association With Self-Reported Disability and Prediction of Mortality and Nursing Home Admission. J Gerontol 1994;49:M85-M94.

44. Rikli R, Jones C. Assessing physical performance in independent older adults: issues and guidelines. J Aging Phys Act 1997;5:244-261.

45. Rikli R, Jones C. Development and validation of a functional fitness test for communityresiding older adults. J Aging Phys Act 1999;7:129-61.

46. Rikli R, Jones C. Senior Fitness Test Manual. Champagne, IL: Human Kinetics; 2001.

47. Turrell G, Haynes M, Burton N, et al. Neighborhood Disadvantage and Physical Activity: Baseline Results from the HABITAT Multilevel Longitudinal Study. Ann Epidemiol 2010;20:171-81. 
48. Turrell G, Hewitt B, Haynes M, Nathan A, Giles-Corti B. Change in walking for transport: a longitudinal study of the influence of neighbourhood disadvantage and individual-level socioeconomic position in mid-aged adults. Int J Behav Nutr Phys Act 2014;11:151.

49. Turrell G, Haynes M, Wilson L, Giles-Corti B. Can the built environment reduce health inequalities? A study of neighbourhood socioeconomic disadvantage and walking for transport. Health Place 2013;19:89-98.

50. Wilson LA, Giles-Corti B, Turrell G. The Association Between Objectively Measured Neighbourhood Features and Walking for Transport in Mid-Aged Adults. Local Environment: The International Journal of Justice and Sustainability 2012;17:131-146.

51. Kamruzzaman, M, Baker D, Washington S, Turrell G. Determinants of residential dissonance: implications for transit oriented development in Brisbane. International Journal of Sustainable Transportation 2016;10:960-974.

52. Bentley R, Blakely T, Kavanagh A, et al. A longitudinal study examining changes in street connectivity, land use, and density of dwellings and walking for transport in Brisbane, Australia. Environ Health Perspect 2018: doi.org/10.1289/EHP2080.

53. van Uffelen JGZ, Khan A, Burton NW. Gender differences in physical activity motivators and context preferences: a population-based study in people in their sixties. BMC Public Health 2017;17:624.

54. Peeters G, Brown WJ, Burton NW. Physical activity context preferences in people with arthritis and osteoporosis. J Phys Act Health 2014;11:536-542.

55. Khan A, Brown WJ, Burton NW. What physical activity contexts do adults with psychological distress prefer? Journal of Science and Medicine in Sport 2013;16:417-421.

56. Burton NW, Khan A, Brown WJ. How, where and with whom? Physical activity context preferences of three adult groups at risk of inactivity. Br J Sports Med, 2012; 46:1125-1131. 
57. Heesch K, Giles-Corti B, Turrell G. Cycling for transport and recreation: associations with socio-economic position, environmental perceptions, and psychological disposition. Prev Med 2014;63:29-35.

58. Heesch K, Giles-Corti B, Turrell G. Cycling for transport and recreation: cross-sectional associations with the socio-economic, natural and built environment. Health Place 2015;36:152-161.

59. Burton NW, Khan A, Brown WJ, Turrell G. The association between sedentary leisure and physical activity in middle-aged adults. Br J Sports Med 2012;46:747-752.

60. Burton NW, Haynes M, van Uffelen JGZ, Brown WJ, Turrell G. Mid-aged adults' sitting time in three contexts. Am J Prev Med 2012;42:363-373.

61. Mielke GI, Burton NW, Turrell G, Brown WJ. Temporal trends in sitting by domain in a cohort of mid-age Australian men and women. Maturitas 2018;116:108-115.

62. Frumkin H, Bratman GN, Breslow SJ, et al., 2017.Nature contact and human health: a research agenda. Environ Health Perspect 2017;125: doi.org/10.1289/EHP1663.

63. Cleary A, Roiko A, Burton NW, et al. Changes in perceptions of urban green space are related to changes in psychological well-being: Cross-sectional and longitudinal study of mid-aged urban residents. Health Place 2019; 50:102201.

64. Hooper P, Foster S, Edwards N, et al. POSitive HABITATS for physical activity: Examining use of public open spaces and its contribution to physical activity levels in midto older-aged adults. Health Place 2020; 63:102308.

65. Dean AJ, Barnett A, Wilson K, Turrell G. Beyond the 'Extinction of Experience' - novel pathways between nature experience and support for nature conservation. Glob Environ Chang 2019; 55:48-57.

66. Turrell G, Hewitt B, Rachele JN, Giles-Corti B, Brown WJ. Prospective trends in body mass index by main transport mode, 2007 - 2013. J Transp Health 2018;8:183-192. 
67. Turrell G, Hewitt B, Rachele JN, Giles-Corti B, Brown WJ. Do active modes of transport cause lower body mass index? Findings from the HABITAT longitudinal study. J Epidemiol Community Health 2018;72:294-301. doi:10.1136/jech-2017-209957.

68. Rachele JN, Kavanagh AM, Brown W, Healy A, Turrell G. Neighborhood disadvantage and body mass index: a study of residential relocation. Am J Epidemiol 2018;187(8):1696-1703.

69. Rachele J, Kavanagh A, Brown W, Healy A, Schmid CJ, Turrell G. Neighborhood socioeconomic disadvantage and body mass index among residentially stable mid-older aged adults: Findings from the HABITAT multilevel longitudinal study. Prev Med 2017;105:271-274.

70. Badland H, Turrell G, Giles-Corti B. Who does well where: exploring how self-rated health differs across diverse people and neighbourhoods. Health Place 2013;22:82-89.

71. Brennan S, Turrell G. Neighbourhood disadvantage, individual-level socioeconomic position, and self-reported chronic arthritis: a cross-sectional multilevel study. Arthritis Care Res 2012;64:721 - 728 .

72. Turrell G, Hewitt B, Miller S. The influence of neighbourhood disadvantage on smoking cessation and its contribution to inequalities in smoking status. Drug Alcohol Rev 2012;31:645-652.

73. Rachele J, Giles-Corti B, Turrell G. Neighbourhood disadvantage and self-reported type 2 diabetes, heart disease and comorbidity: a cross-sectional multilevel study. Ann Epidemiol 2016;26:146-150.

74. Loh HY, Rachele J, Brown W, Washington S, Turrell G. Neighbourhood disadvantage, individual-level socioeconomic position and physical function: a cross-sectional multilevel analysis. Prev Med 2016;89:112-120. 
Figure 1: HABITAT Study conceptual framework

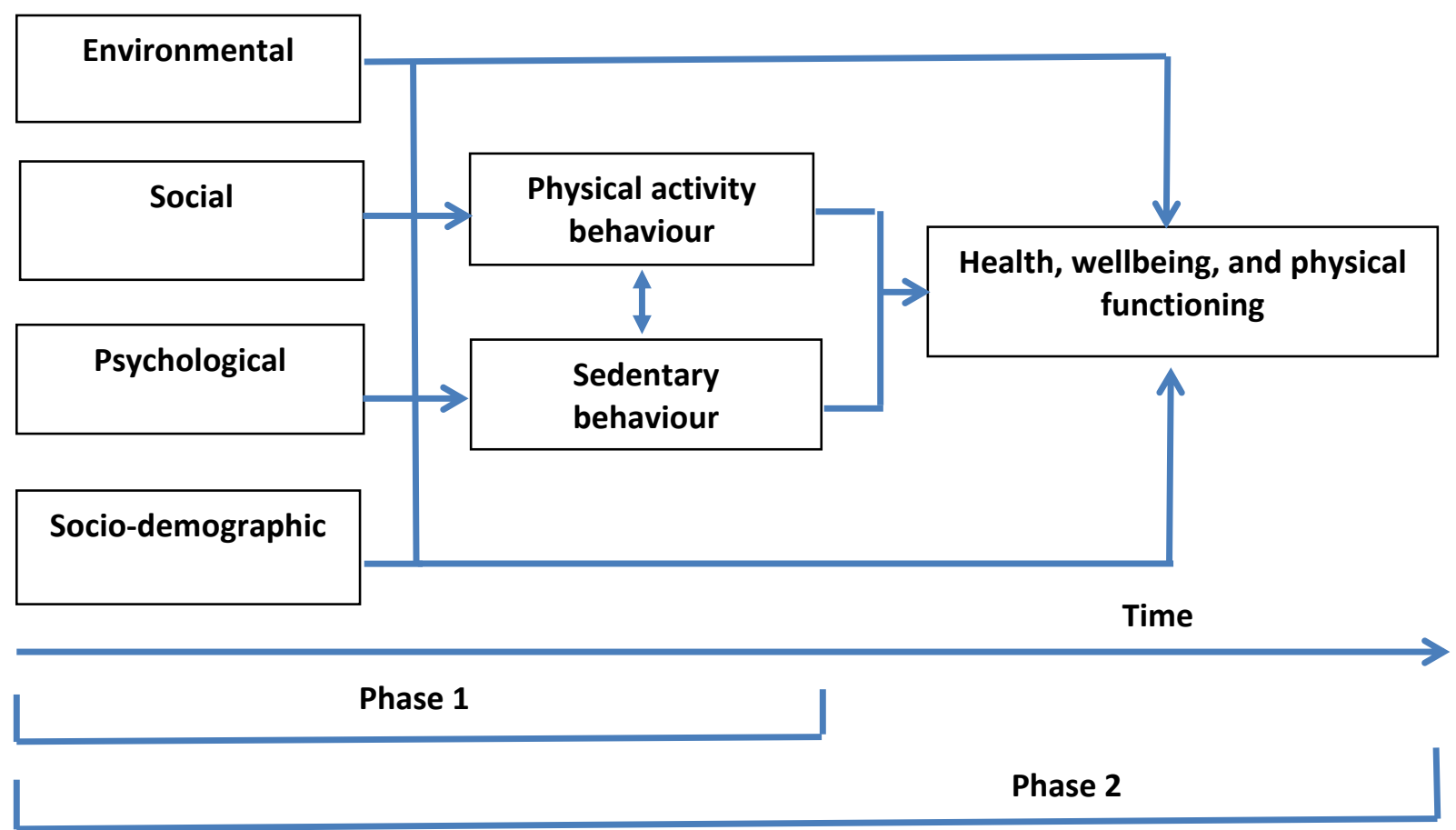


Table 1: Socio-demographic profile of the HABITAT Study cohort at baseline (2007) compared with the Brisbane population aged 40-65 years (2006); and the socio-demographic profile of the HABITAT Study cohort in 2016 (sample participants aged 49-74 years)

\begin{tabular}{|c|c|c|c|c|c|c|}
\hline \multirow[b]{2}{*}{ Sex } & \multicolumn{2}{|c|}{$\begin{array}{l}\text { HABITAT cohort } \\
\text { at baseline (2007) }\end{array}$} & \multicolumn{2}{|c|}{$\begin{array}{c}\text { Brisbane population } \\
\text { aged } 40-65 \text { years }(2006)^{1}\end{array}$} & \multicolumn{2}{|c|}{$\begin{array}{c}\text { HABITAT cohort at } \\
\text { Wave } 5(2016)\end{array}$} \\
\hline & n & $\%$ & $\mathbf{n}$ & $\%$ & n & $\%$ \\
\hline Male & 4,848 & 43.9 & 146,067 & 49.1 & 2,198 & 42.4 \\
\hline Female & 6,187 & 56.1 & 151,213 & 50.9 & 2,989 & 57.6 \\
\hline \multicolumn{7}{|l|}{ Age (years) } \\
\hline $40-44$ & 2,530 & 22.9 & 69,758 & 23.5 & -- & -- \\
\hline $45-49$ & 2,382 & 21.6 & 65,704 & 22.1 & 139 & 2.7 \\
\hline $50-54$ & 2,312 & 21.0 & 59,796 & 20.1 & 1,094 & 21.1 \\
\hline $55-59$ & 2,080 & 18.8 & 55,013 & 18.5 & 1,078 & 20.8 \\
\hline $60-64$ & 1,731 & 15.7 & 40,348 & 13.6 & 1,098 & 21.2 \\
\hline $65-69$ & & & 6,658 & 2.2 & 1,016 & 19.6 \\
\hline $70-74$ & - & - & - & - & 761 & 14.7 \\
\hline \multicolumn{7}{|l|}{ Highest education level attained ${ }^{2}$} \\
\hline Bachelor's degree or higher & 3,457 & 31.3 & 75,414 & 25.4 & 1,882 & 37.0 \\
\hline Diploma/Associate diploma & 1,268 & 11.5 & 28,526 & 9.6 & 618 & 12.2 \\
\hline Certificate (trade/business) & 1,952 & 17.7 & 45,962 & 15.5 & 869 & 17.1 \\
\hline Secondary school or less & 4,311 & 39.1 & 126,777 & 42.6 & 1,699 & 33.4 \\
\hline Missing & 47 & 0.4 & 20,588 & 6.9 & 13 & 0.3 \\
\hline \multicolumn{7}{|l|}{ Occupation } \\
\hline Managers and professionals & 3,688 & 33.4 & 90,597 & 30.5 & 1,563 & 30.1 \\
\hline White collar & 2,433 & 22.0 & 67,314 & 22.6 & 808 & 15.6 \\
\hline Blue collar & 1,580 & 14.3 & 50,000 & 16.8 & 439 & 8.5 \\
\hline Occupation unknown & 832 & 7.5 & -- & -- & 174 & 3.4 \\
\hline Not in the labour force ${ }^{3}$ & 2,004 & 18.2 & 85,987 & 28.9 & 2,106 & 40.6 \\
\hline Missing & 498 & 4.5 & 3,385 & 1.1 & 97 & 1.9 \\
\hline \multicolumn{7}{|l|}{$\begin{array}{l}\text { Gross household income per annum } \\
\text { (AUD) }\end{array}$} \\
\hline$\$ 130,000$ or more & 1,889 & 17.1 & 27,854 & 18.0 & 1,060 & 20.4 \\
\hline$\$ 72,800-\$ 129,999$ & 2,845 & 25.8 & 38,370 & 24.8 & 1,226 & 23.6 \\
\hline$\$ 52,000-\$ 72,799$ & 1,625 & 14.7 & 24,140 & 15.6 & 650 & 12.5 \\
\hline$\$ 41,600-\$ 51,999$ & 813 & 7.4 & 10,354 & 6.7 & 377 & 7.3 \\
\hline$\$ 26,000-\$ 41,599$ & 1,188 & 10.8 & 19,846 & 12.8 & 574 & 11.1 \\
\hline$\$ 0-\$ 25,999$ & 1,044 & 9.5 & 16,148 & 10.4 & 562 & 10.8 \\
\hline Don't know & 270 & 2.4 & -- & -- & 125 & 2.4 \\
\hline Don't want to answer this & 1,147 & 10.4 & -- & -- & 470 & 9.1 \\
\hline Missing & 214 & 1.9 & 17,923 & 11.6 & 143 & 2.8 \\
\hline \multicolumn{7}{|l|}{ Neighbourhood disadvantage ${ }^{4}$} \\
\hline Quintile 1 (least disadvantaged) & 2,613 & 23.7 & 67,016 & 23.5 & 1,317 & 28.4 \\
\hline Q2 & 2,671 & 24.2 & 59,121 & 20.8 & 1,054 & 22.7 \\
\hline Q3 & 2,303 & 20.9 & 56,461 & 19.8 & 885 & 19.1 \\
\hline Q4 & 1,813 & 16.4 & 52,777 & 18.5 & 741 & 16.0 \\
\hline Quintile 5 (most disadvantaged) & 1,635 & 14.8 & 49,360 & 17.3 & 637 & 13.8 \\
\hline
\end{tabular}

1. Based on Australian Bureau of Statistics 2006 Census data (i.e. closest Census to baseline data collection)

2. The survey question pertaining to education was only asked at baseline (2007). Number of participants with valid education data in 2016 was 5,081: those who returned a completed survey in 2016 and who were not the sampled participant in $2007(n=106)$ were excluded from the percentage calculation as their education level was unknown

3. Category includes the retired, home duties, unemployed, and permanently unable to work

4. Quintile 1 contains the $20 \%$ least disadvantaged neighbourhoods (Census Collector Districts) and quintile 5 contains the $20 \%$ most disadvantaged neighbourhoods 
Table 2: HABITAT Study participant attrition: 2007 to 2016

\begin{tabular}{|c|c|c|c|c|c|c|c|c|c|c|}
\hline \multirow[t]{2}{*}{ Wave } & \multicolumn{2}{|c|}{ Respondent } & \multicolumn{2}{|c|}{$\begin{array}{c}\text { Non- } \\
\text { respondent }\end{array}$} & \multicolumn{2}{|c|}{ Withdrawn } & \multicolumn{2}{|c|}{ Deceased } & \multicolumn{2}{|c|}{$\begin{array}{c}\text { Unable to } \\
\text { contact }\end{array}$} \\
\hline & $\mathbf{n}$ & $\%$ & $\mathbf{n}$ & $\%$ & $\mathbf{n}$ & $\%$ & $\mathbf{n}$ & $\%$ & $\mathbf{n}$ & $\%$ \\
\hline Baseline (2007) & 11,035 & & & & & & & & & \\
\hline $1^{\text {st }}$ follow-up (2009) & 7,866 & 71.3 & 2,634 & 23.9 & 377 & 3.4 & 46 & 0.4 & 112 & 1.0 \\
\hline $2^{\text {nd }}$ follow-up (2011) & 6,900 & 62.5 & 2,843 & 25.8 & 923 & 8.4 & 124 & 1.1 & 245 & 2.2 \\
\hline $3^{\text {rd }}$ follow-up (2013) & 6,520 & 59.1 & 3,011 & 27.3 & 1,089 & 9.9 & 170 & 1.5 & 245 & 2.2 \\
\hline $4^{\text {th }}$ follow-up (2016) & 5,187 & 47.0 & 3,401 & 30.8 & 1,606 & 14.6 & 311 & 2.8 & 530 & 4.8 \\
\hline
\end{tabular}


Table 3: Socio-demographic characteristics of the HABITAT clinical sub-study participants: 2014 (baseline) and predictors of loss to follow-up between 2014 and 2016

\begin{tabular}{|c|c|c|c|c|c|c|}
\hline & \multirow{3}{*}{$\begin{array}{c}\text { Baseline } \\
\text { sample, 2014 } \\
(\mathrm{n}=767) \\
\%\end{array}$} & \multirow{3}{*}{$\begin{array}{c}\text { Follow-up } \\
\text { sample, 2016 } \\
(\mathbf{n}=606) \\
\%\end{array}$} & \multicolumn{4}{|c|}{ Loss to follow-up in $2016(n=161)^{1}$} \\
\hline & & & \multicolumn{2}{|c|}{ Model $1^{2}$} & \multicolumn{2}{|c|}{ Model $2^{3}$} \\
\hline & & & OR & $95 \% \mathrm{CrI}$ & OR & $95 \% \mathrm{CrI}$ \\
\hline \multicolumn{7}{|l|}{ Sex } \\
\hline Female & 59.8 & 60.2 & 1.00 & & & \\
\hline Male & 40.2 & 39.8 & 1.07 & $0.65,1.34$ & 1.03 & $0.65,1.45$ \\
\hline \multicolumn{7}{|l|}{ Age (years) } \\
\hline $45-49$ & 14.2 & 14.4 & 1.00 & & 1.00 & \\
\hline $50-54$ & 21.4 & 21.3 & 1.08 & $0.59,1.96$ & 1.13 & $0.60,2.14$ \\
\hline $55-59$ & 20.9 & 20.3 & 1.20 & $0.66,2.19$ & 1.14 & $0.61,2.14$ \\
\hline $60-64$ & 20.2 & 20.3 & 1.04 & $0.57,1.92$ & 0.94 & $0.48,1.81$ \\
\hline $65-69$ & 18.9 & 19.3 & 0.95 & $0.51,1.80$ & 0.77 & $0.38,1.56$ \\
\hline $70-74$ & 4.4 & 4.5 & 0.99 & $0.35,2.55$ & 0.85 & $0.28,2.44$ \\
\hline \multicolumn{7}{|l|}{ Highest education level attained } \\
\hline Bachelor's degrees or higher & 42.0 & 44.2 & 1.00 & & 1.00 & \\
\hline Diploma/ Associate diploma & 11.6 & 10.7 & 1.86 & $1.05,3.24$ & 1.65 & $0.90,2.99$ \\
\hline Certificate (trade/ business) & 16.6 & 17.2 & 1.08 & $0.62,1.86$ & 0.84 & $0.45,1.52$ \\
\hline Secondary school or less & 29.6 & 27.9 & 1.73 & $1.13,2.67$ & 1.35 & $0.82,2.25$ \\
\hline Missing & 0.3 & 0.0 & -- & -- & -- & -- \\
\hline \multicolumn{7}{|l|}{ Occupation } \\
\hline Managers and professionals & 37.4 & 38.8 & 1.00 & & 1.00 & \\
\hline White collar & 20.1 & 19.8 & 1.28 & $0.76,2.11$ & 0.95 & $0.54,1.69$ \\
\hline Blue collar & 9.3 & 8.3 & 1.92 & $1.02,3.52$ & 1.47 & $0.72,2.97$ \\
\hline Occupation unknown & 2.5 & 2.2 & 1.14 & $0.68,1.90$ & 0.88 & $0.50,1.55$ \\
\hline Not in the labour force & 28.3 & 28.9 & 2.05 & $0.68,5.93$ & 1.31 & $0.39,4.06$ \\
\hline Missing & 2.5 & 2.2 & 2.09 & $0.69,5.95$ & 1.76 & $0.55,5.20$ \\
\hline \multicolumn{7}{|l|}{$\begin{array}{l}\text { Gross Household income per } \\
\text { annum (AUD) }\end{array}$} \\
\hline$\$ 130,000$ or more & 23.2 & 25.1 & 1.00 & & 1.00 & \\
\hline$\$ 72,800-\$ 129,999$ & 27.0 & 27.1 & 1.67 & $0.96,2.93$ & 1.53 & $0.86,2.70$ \\
\hline$\$ 52,000-\$ 72,799$ & 12.1 & 11.6 & 2.27 & $1.16,4.41$ & 1.92 & $0.95,3.88$ \\
\hline$\$ 41,600-\$ 51,999$ & 7.8 & 7.9 & 1.78 & $0.79,3.93$ & 1.41 & $0.58,3.33$ \\
\hline$\$ 26,000-\$ 41,599$ & 10.3 & 9.4 & 3.02 & $1.47,6.10$ & 2.51 & $1.15,5.52$ \\
\hline$\$ 0-\$ 25,999$ & 11.1 & 10.9 & 2.25 & $1.07,4.68$ & 1.85 & $0.83,4.12$ \\
\hline Don’t know & 1.4 & 1.3 & 2.42 & $0.49,10.10$ & 1.96 & $0.37,8.86$ \\
\hline Don't want to answer this & 5.6 & 5.5 & 2.13 & $0.87,4.95$ & 1.88 & $0.72,4.76$ \\
\hline Missing & 1.4 & 1.3 & 2.29 & $0.45,9.48$ & 2.20 & $0.43,9.07$ \\
\hline \multicolumn{7}{|l|}{ Neighbourhood disadvantage } \\
\hline Quintile 1 (Least disadvantaged) & 29.7 & 31.2 & 1.00 & & 1.00 & \\
\hline Q2 & 13.4 & 13.5 & 1.23 & $0.64,2.30$ & 1.15 & $0.58,2.19$ \\
\hline Q3 & 21.9 & 21.0 & 1.60 & $0.94,2.72$ & 1.46 & $0.84,2.54$ \\
\hline Q4 & 18.5 & 19.0 & 1.17 & $0.66,2.07$ & 0.99 & $0.54,1.80$ \\
\hline Quintile 5 (Most disadvantaged) & 16.4 & 15.4 & 1.79 & $1.03,3.14$ & 1.32 & $0.72,2.41$ \\
\hline
\end{tabular}

1. Modelled using multilevel logistic regression, with model parameters (expressed as odds ratios and $95 \%$ credible intervals) estimated by Markov chain Monte Carlo simulation using MLwiN software (33)

2. Age and sex adjustment only

3. Simultaneous adjustment for all sociodemographic characteristics

4. Quintile 1 contains the $20 \%$ least disadvantaged neighbourhoods (Census Collector Districts) and quintile 5 contains the $20 \%$ most disadvantaged neighbourhoods 